\title{
Efficacy and Safety Evaluation of Sildenafil Citrate in the Form of 50 mg Orodispersible Tablets Controlled by Placebo
}

\author{
Maria Antonieta Annunziato ${ }^{*}$, Di Capua Teodoro ${ }^{2}$, Dieguez Vicente², Ledos Luis ${ }^{2}$, Koury Mufid ${ }^{2}$ \\ ${ }^{1}$ Department of Internal Medicine, Medical Attention Center, BANDESIR, Caracas, Venezuela \\ ${ }^{2}$ Department of Urology, Domingo Luciani Hospital, Caracas, Venezuela \\ Email: ^annunziato.maria@gmail.com
}

How to cite this paper: Annunziato, M.A., Teodoro, D.C., Vicente, D., Luis, L. and Mufid, K. (2018) Efficacy and Safety Evaluation of Sildenafil Citrate in the Form of $50 \mathrm{mg}$ Orodispersible Tablets Controlled by Placebo. Case Reports in Clinical Medicine, 7 , 249-258.

https://doi.org/10.4236/crcm.2018.73023

Received: February 7, 2018

Accepted: March 20, 2018

Published: March 23, 2018

Copyright $\odot 2018$ by authors and Scientific Research Publishing Inc. This work is licensed under the Creative Commons Attribution International License (CC BY 4.0).

http://creativecommons.org/licenses/by/4.0/

(c) (i) Open Access

\begin{abstract}
Purpose: To evaluate the efficacy and safety of sildenafil in orodispersable tablets of $50 \mathrm{mg}$ vs. placebo in men with erectile dysfunction (ED). Methods: A blind, comparative, placebo controlled, randomized study was developed in 106 patients with ED. They randomly received sildenafil orodispersable $50 \mathrm{mg}$ (Group I) or placebo (Group II) 3 times per week, 1 hour before sexual activity, during 4 weeks. The efficacy was evaluated by IIEF- 5 and the adverse events (AE) by poll. Results: After 4 weeks a percentage improvement of the ED was observed in Group I patients $44 \%$ of whom became without ED vs. $2 \%$ of Group II, with an additional statistical significant improvement evidenced respect to the placebo in the IIEF-5 score from $13.7 \pm 4.9$ to $19.9 \pm 4.4$ vs. $13.1 \pm 4.0$ to $17.8 \pm 4.9$ in the placebo group, Confidence Interval (CI95\%): 19.90 vs. 13.98 , respectively, $\mathrm{p}<0.001$. Regarding the basal value, a total increment of the IIEF- 5 was observed, at the end of the 4 weeks treatment of $60 \%$ in Group I vs. $10 \%$ in Group II. In Group I was evidenced an statistical significant improvement of the IIEF- 5 in each of the 5 questions at the end of the 4 weeks, specially in questions 3,4 , and 5 related to keeping the erection and satisfaction $(\mathrm{p}<0.0001)$. The AE were mild, transient and could be tolerated. No patient dropped out because AE. Conclusions: Sildenafil was superior to placebo, substantially improved the IIEF-5 scores, showing a statistical significant therapeutic response in the ED treatment and it was safe and well tolerated.
\end{abstract}

\section{Keywords}

Erectile Dysfunction, Sildenafil, Orodispersable Tablets 


\section{Introduction}

Erectile dysfunction (ED) is defined as the inability to achieve and/or maintain an erection sufficient for a satisfactory sexual intercourse, a pathology of high repercussion and frequency in the male population, specially as they become older. It is also associated with neurological and endocrine sickness, as well as with medicament such as beta-blockers or methyldopa and factors that modify the lifestyle such as tobacco addiction and excessive alcohol consumption. The ED has consequences not only physical but psychological of great relevance to couple's lives [1]. Epidemiological studies have demonstrated that ED is a very frequent pathology. For practical purposes it can be said that at age 40 close to $40 \%$ of male population suffers from some degree of erectile dysfunction. The epidemiological study DENSA (Disfunción Eréctil en el Norte de Suramérica-ED in the North of South América) developed in Colombia, Venezuela and Ecuador, in which 1946 males older than 40 years were interviewed, is the more direct evidence that exists on this issue in our country. This study revealed a 53\% ED incidence in men older than 40 in the North of South America [2] [3].

The Sildenafil Citrate is a powerful selective inhibitor of phosphodiesterase type-5 (PDE 5), which is the predominant isozyme that inactivates cyclic guanosine monophosphate (GMP-c) in the corpus cavernosum of the penis. In the presence of a sexual stimulus and under the influence of the liberation of nitric oxide by the nerves of the penis, increases the concentration of GMP-c, and due to this reason, when it does not degrade, it helps the achievement of erection [4] [5] [6]. The daily dose usually recommended is $25-50 \mathrm{mg}$, and should not exceed $100 \mathrm{mg} /$ day [7] [8]. The safety results in 550 subjects treated for at least one year demonstrated that this medicament is well tolerated [9] [10], and the incidence of adverse effects (AE) has been reported in the literature as: Neurologic. Headaches, dizziness. Cardiovascular. Blushing, mild transitory hypotension. Digestive: Dyspepsia. Ophthalmologic. Mild and transitory visual disorders such as abnormal color vision, increasing light perception or blurry vision [11] [12] [13].

During medical consultation at "Domingo Luciani" Hospital in 1999, a high prevalence of erectile dysfunction was found in male patients seeking evaluation, especially in those between 40 to 70 years old range (64\% of 579 patients) [3]. This research protocol fully satisfied the recommendations for clinical trials, drugs evaluation and the ethical principles of the Helsinki Declaration, reviewed in latest world conferences and current legislation [14]. Additionally it was approved by "Domingo Luciani" Hospital Institutional Ethical Committee. The aim of this study was to evaluate the efficacy and safety of $50 \mathrm{mg}$ Sildenafil orodispersible tablets vs. placebo in males with ED.

\section{Materials and Methods}

300 male patients were preselected and extracted from a total population of 3345 males that came to "Domingo Luciani" Hospital, in a period of 18 months (April 
2014 to September 2015), taking as a criterion their willingness to participate in a study to evaluate ED. They were called by press, radio and television advertise for prostate cancer check-up promoted by the coordinators of the Hospital's Urology Graduate Studies Department. 200 of those patients, who manifested having ED, were pre selected after a conference given to them. Finally, $106 \mathrm{pa}-$ tients were selected in the range of 32 to 67 years old, fully complying with inclusion criteria, after a comprehensive medical evaluation and having determined the ED via the International Index of Erectile Function (IIEF-5) [15] [16] [17]. Responses to each of the five items on the IIEF-5, which are based on a rating scale from 0 to 5 or from 1 to 5 (depending on the item), are summed to arrive at a total score that can range from 1 to 25 , with higher scores indicating better sexual health. ED was defined as the inability to achieve or maintain an erection sufficient for satisfactory sexual intercourse. The diagnosis was confirmed with a score of $<21$ in the IIEF-5. The degree of severity of ED was classified, according to IIEF-5 score, in mild (18 to 21 ); moderate (10 to 17), severe (5 to 9) [15] [16] [17].

\subsection{Inclusion Criteria}

1) To have signed an informed consent prior to the incorporation to this research.

2) To be male subjects older than 18 years old.

3) Not to have history or background of alcohol and/or drug addiction.

4) To have high probabilities of compliance with established procedures of this research protocol, namely: intake of tablets, weekly visits follow up and additional requirements to successfully finish the study.

5) To be patients classified with erectile dysfunction confirmed by the mentioned IIEF-5.

6) To have a stable partner.

\subsection{Exclusion Criteria}

1) To be hypersensitive to the drug studied.

2) To have a background or condition that might be considered as a risk factor in sildenafil intake, according to the criteria of the Medical Researcher.

3) To be a subject that receives or has received any kind of drug prior to the start of the study, among them phosphodiesterase inhibitor, without prior authorization of the Medical Researcher.

4) To be subject that has been receiving drugs that interact with the drug researched (givers of nitric oxide or nitrates in any of its pharmaceutical forms, antiplatelet, warfarin, alcohol, cimetidine, erythromycin and ketoconazole).

5) To be subjects with cardiovascular diseases, oclusive arterial disease, liver or kidney failure, hereditary retinitis pigmentosa, history of priapism or sickenesses that predispose to the same (Sickle cell anemia, multiple myeloma or leukemia), blood dyscrasias, active peptic ulcer, and infection. 
6) "To have an IIEF $\geq 22$ points".

7) Others: Prior prostatic surgery, pelvic trauma, prostate cancer, or subjects that are receiving treatment for prostate cancer.

In this phase III study blind, randomized, placebo controlled, and after having written informed consent recruited patients were divided in 2 groups and were scheduled to receive codified tablets. This was done with prior training in the way of intake, finally being arranged in the following manner (Figure 1):

Group I [ $=54$ ]: Sildenafil orodispersible $50 \mathrm{mg}$ tablets (Dugasek ${ }^{\circledast} /$ Leti) [Encoded SPSA]. 1 orodispersible tablet in the mouth until dissolved (no chewing).

Group II [ $\mathbf{n}=\mathbf{5 2}$ ]: Placebo orodispersible tablets (Encoded SNA). 1 orodispersible tablet in the mouth until dissolved (no chewing).

All patients, by group of study, were instructed with a conference prior to the intake of 1 tablet 3 times per week (Mondays, Wednesdays and Fridays), one hour before sexual intercourse during a period of 4 weeks. After the incorporation of patients to the trial, they were subjected to a weekly performance follow up and medical evaluation by urologists and an internist. For the erectile dysfunction and clinical efficacy a questionary for sexual male health was used based on IIEF-5. As reported above, it was designed to produce a diagnostic instrument summarized in 5 questions which embedded a high degree of sensitivity and specificity. AE were evaluated by poll/inquiry [8] [9] [10] [11] [12]. For

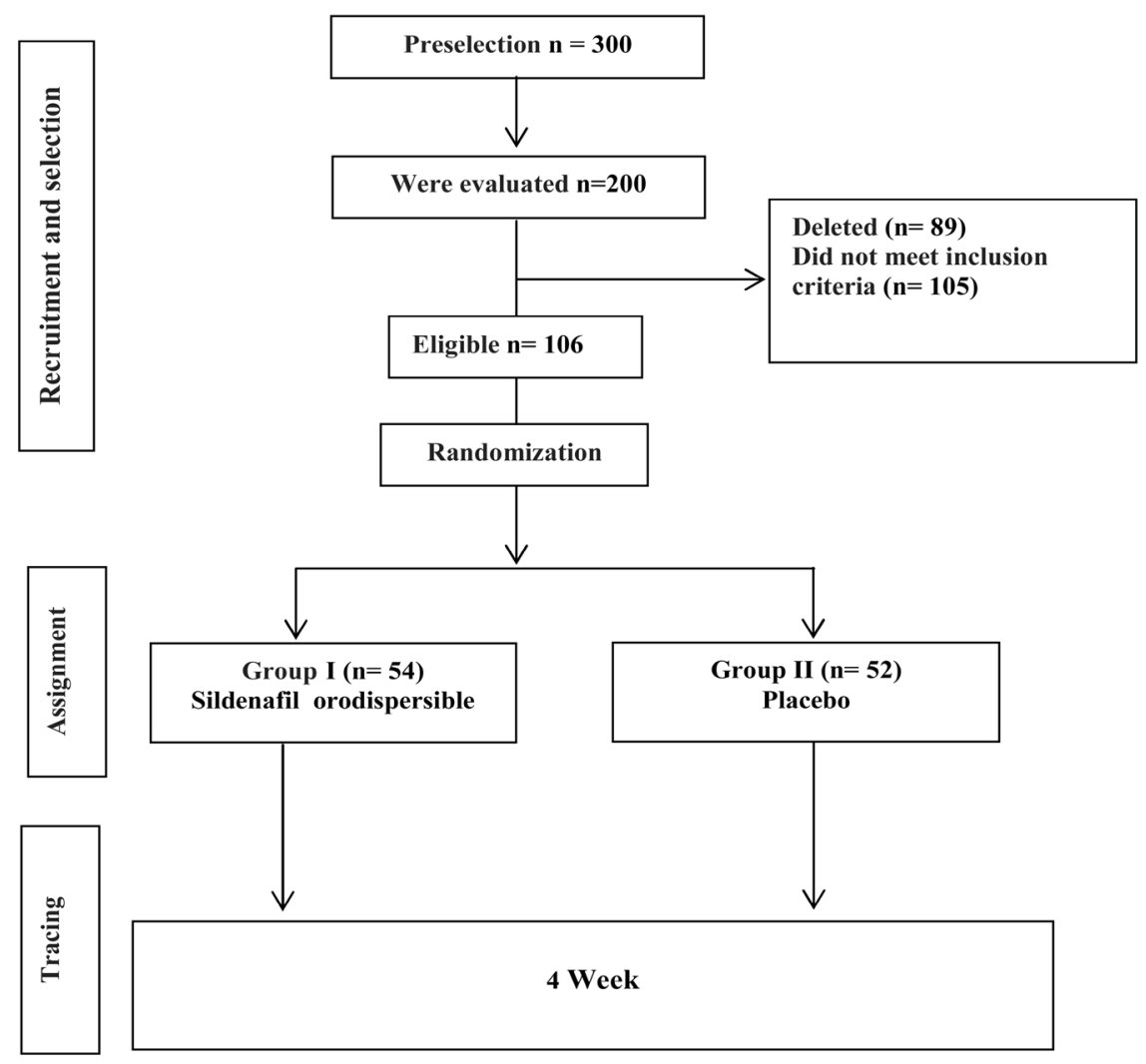

Figure 1. Selection scheme, treatment allocation and follow-up. 
the analysis of results an Informatic Statistical Software SPSS 17.0 was used. For the statistical analysis the t-Student test was used with a 95\% Confidence Interval (CI). The protocol for this study was also approved by the Ethics Committee of the "Domingo Luciani" Hospital.

\section{Results}

This study started with 106 patients and ended with 102 because during its execution four patients were excluded due to non compliance with point 4 of the above captioned inclusion criteria. The average age of patients evaluated was 53.6 years and according to the IIEF- 5 all had a degree of ED (Table 1 ).

The degree of severity of the ED before initiating the treatment was in Group I: Mild 28\%, moderate $48 \%$ and severe 24\% (Table 2), while in Group II: Mild $13.46 \%$, moderate $67.30 \%$ and severe $19.23 \%$ (Table 3 ). At the end of the 4 weeks of treatment, the degree of severity of ED evolved, improving in Group I. Specifically: Without dysfunction $44 \%$, mild $36 \%$, moderate $14 \%$ and severe $6 \%$ (Table 2), while in Group II: Without dysfunction $1.92 \%$, mild 19.23\%, moderate $61.53 \%$ and severe $17.31 \%$ (Table 3 ). For Group I, at the end of the 4 week, an statistical significant improvement was evidenced respect to the placebo, in the score sheet of the IIEF-5 from $13.7 \pm 4.9$ to $19.9 \pm 4.4$ vs. $13.1 \pm 4.0$ to $17.8 \pm$ 4.9 in the placebo group (CI $95 \%$ : 19.90 vs. 13.98 , respectively, $\mathrm{P}<0.001$ ).

Table 1. Demographic Data by group of study.

\begin{tabular}{|c|c|c|c|c|c|c|c|}
\hline & Grour & $\mathrm{p} I(\mathrm{n}=50)$ & & & Group & $\mathrm{p}$ II $(n=52)$ & \\
\hline Age Rang & \#Persons & Average Age & IIEF-5 Basa & Age Range & \#Persons & Average Age & IIEF-5 Basal \\
\hline$\leq 40$ & 1 & 32,0 & 20 & $\leq 40$ & 1 & 39.0 & 8.0 \\
\hline $41-45$ & 4 & 42.8 & 10.5 & $41-45$ & 10 & 43.7 & 12.7 \\
\hline $46-50$ & 9 & 48.6 & 15.0 & $46-50$ & 8 & 47.6 & 12.9 \\
\hline $51-55$ & 14 & 54.0 & 15.4 & $51-55$ & 13 & 53.2 & 14.2 \\
\hline $56-60$ & 17 & 57.8 & 12.6 & $56-60$ & 13 & 58.6 & 13.7 \\
\hline $61-65$ & 4 & 61.5 & 11.0 & $61-65$ & 5 & 62.2 & 13.0 \\
\hline$\geq 66$ & 1 & 66.0 & 13.0 & $\geq 66$ & 2 & 66.5 & 8.5 \\
\hline
\end{tabular}

Table 2. Severity of the ED by groups of study, before the products intake and its evolution until the end of the 4 week, in accordance with IIEF-5. Group I.

\begin{tabular}{ccc}
\hline $\begin{array}{c}\text { Severity of the ED } \\
(\mathbf{n}=\mathbf{5 0})\end{array}$ & Basal & $\mathbf{4}$ Week \\
\hline Without Dysfunction & $0 \%$ & $44 \%$ \\
Mild & $28 \%$ & $36 \%$ \\
Moderate & $48 \%$ & $14 \%$ \\
Severe & $24 \%$ & $6 \%$ \\
\hline
\end{tabular}


In reference to the weekly behavior of the IIEF-5, a progressive increment is observed that reaches its peak at the fourth week, in Group I; while the same trend was NOT observed in Group II $(\mathrm{p}<0.001)$. With respect to the baseline value, a total increase of IIFE-5 is observed, at the end of the 4 weeks of treatment of $60 \%$ of patients in Group IA vs. $10 \%$ of the placebo group (Figure 2).

In Table 4 one observes a statistical significant improvement of the IIEF-5 at

Table 3. Severity of the ED by groups of study, before the products intake and its evolution until the end of the 4 week, in accordance with IIEF-5. Group II.

\begin{tabular}{ccc}
\hline $\begin{array}{c}\text { Severity of the ED } \\
(\mathrm{n}=\mathbf{5 2})\end{array}$ & Basal & $\mathbf{4}$ Week \\
\hline Without Dysfunction & $\mathbf{0 \%}$ & $1.92 \%$ \\
Mild & $13.46 \%$ & $19.23 \%$ \\
Moderate & $67.30 \%$ & $61.53 \%$ \\
Severe & $19.23 \%$ & $17.31 \%$ \\
\hline
\end{tabular}

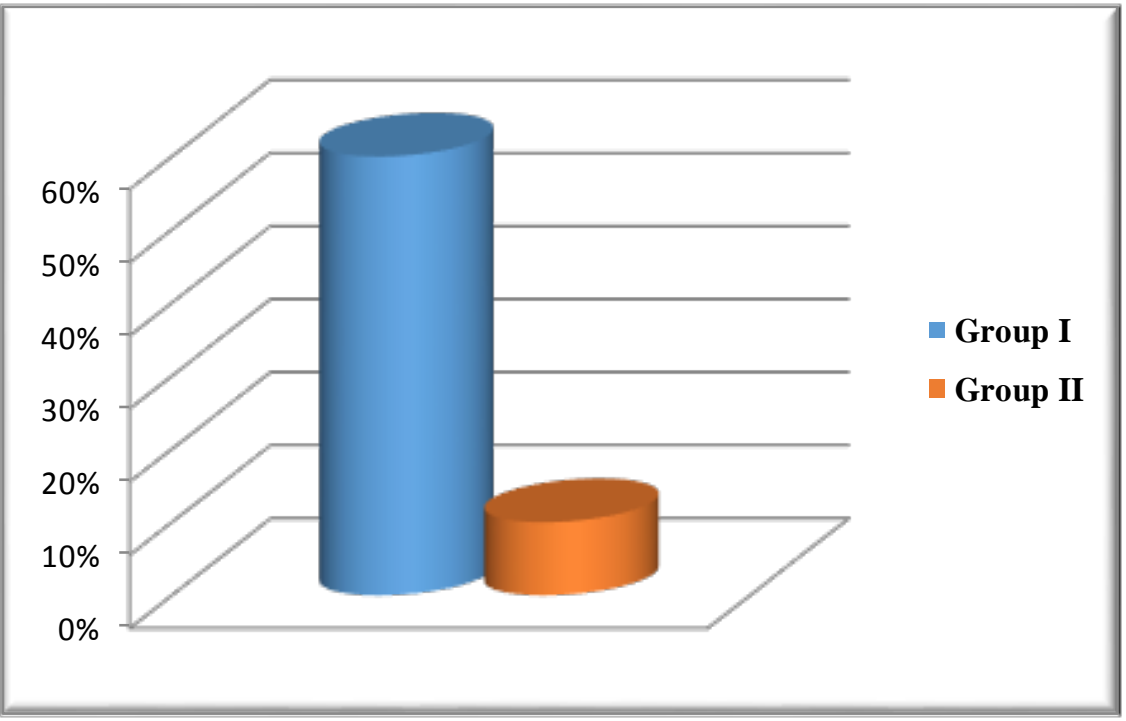

Figure 2. Total Increment of the IIEF-5 (\%) by group of study at the end of the 4 week.

Table 4. IIEF-5 at the end of of the 4 week in the group that received the active principle.

\begin{tabular}{|c|c|c|c|c|}
\hline & \multirow[b]{2}{*}{ Questions } & \multicolumn{2}{|c|}{ Grading for each question } & \\
\hline & & Basal & 4 Week & \\
\hline 1 & Confidence to perform the sexual intercourse & $2.16 \pm 0.91$ & $3.38 \pm 0.87$ & $\mathrm{p}<0.002$ \\
\hline 2 & Erection Firmness to achieve penetration & $2.46 \pm 1.37$ & $4.02 \pm 1.03$ & $\mathrm{p}<0.001$ \\
\hline 3 & Erection Maintenance after penetration & $2.58 \pm 1.24$ & $4.06 \pm 1.07$ & $\mathrm{p}<0.0001$ \\
\hline 4 & Erection Maintenance until the end & $3.18 \pm 1.64$ & $4.42 \pm 1.05$ & $\mathrm{p}<0.0001$ \\
\hline \multirow[t]{2}{*}{5} & Erection Satisfaction & $3.28 \pm 1.27$ & $4.04 \pm 1.15$ & $\mathrm{p}<0.0001$ \\
\hline & Total & $13.7 \pm 4.9$ & $19.9 \pm 4.4$ & \\
\hline
\end{tabular}


the end of the 4 week the treatment, in the group that received the active principle (Dugasek ${ }^{\odot}$ ), specially in questions 3, 4 and 5 related to the maintenance of erection and satisfaction of the same $(\mathrm{p}<0.0001)$.

The most frequent adverse events by group of study were: Group I: flushing (16\%); headache (14\%); dyspepsic complaints (6\%); red eyes (4\%), nasal congestion (2\%) vs. Group II: headache (4\%); flushing (2\%); red eyes (2\%). These AE were mild, transitory and tolerated. No patient dropped out because AE. No significant safety problems were found.

\section{Discussion}

The appearance of sildenafil, as the first medicament to treat the ED, unleashed an avalanche of research and knowledge regarding the challenges of this pathology worldwide [18] [19] [20] [21]. The IIEF term abridged is the most used internationally to classify the ED and evaluate the same after any treatment [15] [17]. It was used in this research.

In a multidimensional multicenter study that evaluated the efficacy of sildenafil in 22 patients that were hemodyalized with ED, it was uncovered that $36,4 \%$ of the patients manifested a mild dysfunction, $50 \%$ moderate and $13.6 \%$ severe. This happened before initiating the treatment. At the end of the treatment, the ED evolved improving so that: Without dysfunction, in $13.6 \%$ of the patients; mild, in $40.9 \%$; moderate, in $36.4 \%$ and remained severe in $9.1 \%$ [16]. In another study which included 32 patients with ED that also evaluated the efficacy of sildenafil it was found that $9.3 \%$ showed a mild dysfunction, $71.8 \%$ moderate and $18 \%$ severe, before initiating the treatment. After 4 weeks of treatment the ED evolved improving, namely: Without dysfunction $18.7 \%$, mild 59.3\%, moderate $12.5 \%$ and severe $9.3 \%$ [21].

In this research, at the end of the 4 week of treatment, the ED evolved, improving in those patients that received the active principle. Specifically a: Without dysfunction $44 \%$, mild $36 \%$, moderate $14 \%$ and severe $6 \%$ (Table 2 ). There was no good evolution in the group of patients that received the placebo (Table 3). On the other hand, in this research, in the group that received placebo, it was observed a discrete, small increment of the mild ED. This could be explained by the fact that the pattern of response to the placebo is transitory and tends to decrease with time. Thus, with the use of placebo, this is one of the phenomena that must be considered in the responses of short duration obtained with the oral treatments for ED, specially in those patients that show a depressive substratum [18].

In a study that included 20 patients with ED without associated comorbidity, developed to evaluate the clinical efficacy of a new chewable sildenafil presentation, equivalent to $50 \mathrm{mg}$ of the traditional presentation. It is noticeable that using this pharmacological presentation $95 \%$ of the patients showed an improvement of 3 points or more in the IIEF- 5 results when comparing performance before and after treatment. This difference is significant with a $\mathrm{P}$ value $<0.05$ 
[12]. In this clinical trial for Group I patients that received the active principle, at the 4 week, it was evidenced an statistical significant improvement respect to the placebo, in the scoresheet of the IIEF-5 from $13.7 \pm 4.9$ to $19.9 \pm 4.4$ vs. $13.1 \pm$ 4.0 to $17.8 \pm 4.9$ in the placebo group (Media of CI 95\%: 19.90 vs. 13.98 , respectively, $\mathrm{p}<0.001)$. In the same manner, respect to the basal, a total increment of the IIEF- 5 was observed, of $60 \%$ in Group I vs. $10 \%$ in Group II. In a multicenter study that evaluated the efficacy of sildenafil in 22 patients hemodyalized with $\mathrm{ED}$, it was observed, at the end of the study, an improvement of the scoresheet of the IIEF-5, specially in questions 1 and 5, related to the confidence in fulfilling the sexual intercourse $(\mathrm{p}<0.001)$ and the satisfaction of the same $(\mathrm{p}<0.001)$. Only category entitled "erection maintenance until the end" was not statistical significant $\mathrm{p}>0.05$ (initial 2.66 vs. final 3.04) [16]. In this research it was observed a statistical significant improvement of the IIEF- 5 in each of the 5 questions at the end of the treatment, specially in questions 3 , 4 y 5 related to the maintenance of the erection and satisfaction of the same $(\mathrm{p}<0.0001)$.

In a study performed in 20 patients with erectile dysfunction that received chewable sildenafil with follow up lower than 4 weeks ( 1 week), 18 of the 20 patients showed adverse effects: Headache 6; flushing 6; red eyes 1; pruritus/itch 1, dyspeptic complaints 1 , nasal congestion 2 ; heart beatings 1 [12]. In another study that included 22 patients with ED in hemodyalisis, adverse events were manifested in $54.5 \%$ of the subjects. These AE were mild and transitory. They were the following in frequency order: Headache (30\%); flushing (27.5\%) and nasal congestion (24\%). It was concluded that Sildenafil, even in those patients, was safe effective [16]. In another clinical trial where it was evaluated the efficacy and tolerance of sildenafil in 125 patients with ED where 117 (94\%) were included in the tolerance analysis and 114 in the efficacy (97\%). It was observed that in 36/117 (31\%) of the cases patients manifested AE related with medicament. The most frequent $\mathrm{AE}$ were: Headache in 18 subjects (15\%); flushing in 10 (8.5\%) and nasal congestion in 3 (2.6\%). All AE were mild and moderated [10].

In this clinical trial the most frequent adverse events by group of study were: Group I: flushing (16\%); headache (14\%); dyspepsic complaints (6\%); red eyes (4\%), nasal congestion (2\%) vs. Group II: Headache (4\%); flushing (2\%); red eyes $(2 \%)$. These $\mathrm{AE}$ were mild, transitory and well tolerated. It did not require discontinuing the treatment in none of the patients evaluated. These AE were no different than the ones described in other studies published of sildenafil in other forms of pharmacological presentation [12] [22] [23].

\section{Conclusion}

Sildenafil in orodispersible tablets was superior to placebo, significantly improved IIEF-5 scores compared with pretreatment values, showing a statistical significant therapeutic response in the ED treatment. Additionally it was safe and well tolerated and did not require discontinuing the treatment due to $\mathrm{AE}$ in none of the patients evaluated. 


\section{Conflict of Interests}

The authors declare that there is no conflict of interest regarding the publication of this paper.

\section{References}

[1] (1993) NIH Consensus Conference: Erectile Dysfunction. NIH Consensus Development Panel on ED. JAMA, 270, 83-90. https://doi.org/10.1001/jama.270.1.83

[2] Morillo, L.V. (1999) Meeting of the Latin American Society for the Study of Impotence (SLAI) Oct.

[3] Teodoro, S.G., Ricardo, S.N., Di Capua, T., et al. (2001) Epidemiology of Male Sexual Dysfunction in Venezuela. Venezuelan Journal of Urology, 47, 37-40.

[4] Gunter, G. and Trummer, H. (2003) The Etiology of Erectile Dysfunction and Mechanisms by Which Drugs Improve Erection. Drugs of Today, 39, 193-201. https://doi.org/10.1358/dot.2003.39.3.740216

[5] Langtry, H. and Markham, A. (1999) Sildenafil, a Review of Its Use in Erectile Dysfunction. Drugs, 57, 967-989. https://doi.org/10.2165/00003495-199957060-00015

[6] Abramowicz, M. (1998) Sildenafil: An Oral Drug for Impotence. The Medical Letter, 40, 51-52.

[7] Bradley, N., Christ, J. and Melman, A. (1999) Sildenafil: A New Oral Therapy for Erectile Dysfunction. Drug of Today, 35, 211-217. https://doi.org/10.1358/dot.1999.35.3.533850

[8] Goldstein, I., Lue, T.F., Padma-Nathan, H., et al. (1998) For the Sildenafil Study Group. Oral Sildenafil in the Treatment of Erectile Dysfunction. The New England Journal of Medicine, 38, 1397-1404. https://doi.org/10.1056/NEJM199805143382001

[9] Paragano, A.J., Curotto Grasiosi, J., Pelliza, M., et al. (2005) Cardiovascular Effects and Therapeutic Indications of Sildenafil. Rev CONAREC Julio, 8, 104-109.

[10] Manuel, D.-D. (2007) Efficacy and Satisfaction with the Firmness of the Erection with Rapid Scaling of the Dose of Sildenafil 50 to $100 \mathrm{mg}$ in Men with Erectile Dysfunction. Mexican Journal of Urology, 67, 35-48.

[11] Review Board of Pharmaceutical Products. Bulletin No. 33: 27. Instituto Nacional de Higiene "Rafael Rangel”. República Bolivariana de Venezuela. http://www.inhrr.gob.ve/pdf/pdf_jr/33.pdf

[12] Flores, J.M., et al. (2007) Chewable Sildenafil, Prospective Analysis of New Pharmacological Presentation. Chilean Journal of Urology, 72, 181-184.

[13] Cappelleri, J.C., et al. (2000) Relationship between Patient Self-Assessment of Erectile Function and the Erectile Function Domain of the International Index of Erectile Function. Urology, 56, 477-481. https://doi.org/10.1016/S0090-4295(00)00697-X

[14] Declaration of Helsinki. Adopted by the 18th Medical Assembly; Helsinki, Finland, June 1964 and amended by the 59th General Assembly, Seoul, Korea, October 2008. http://www.wma.net/es/30publications/10policies/b3/index.html.pdf?print-media-t ype\&footer-right=[page]/[toPage $]$

[15] Rosen, R.C., Riley, A., Wagner, G., Osterloh, I.H., Kirkpatrick, J. and Mishra, A. (1997) The International Index of Erectile Function (IIFE): A Multidimensional Scale for Assessment of Erectile Dysfunction. Urology, 49, 822-830. https://doi.org/10.1016/S0090-4295(97)00238-0 
[16] Pérez-Oliva, J.F., García, O., del Carmen Castillo, M., et al. (2008) Experience with Oral Sildenafil in Hemodialysis Patients. Multicenter Study. Habanera Journal of Medical Sciences, 7.

[17] Rosen, R.C., Cappelleri, J.C. and Gendrano, N. (2002) The International Index of Erectile Function (IIEF): A State-of-the-Science Review. International Journal of Impotence Research, 14, 226-244. https://doi.org/10.1038/sj.ijir.3900857

[18] Silva, J.M. (2002) Placebo Effect and Erectile Dysfunction. Urología Colombiana: Comité Editorial, 11, 17-21.

https://encolombia.com/medicina/revistas-medicas/urologia/vu-112/urologia11202efecto2/

[19] Morales, A., Gingell, C., Collins, M., Wicker, P.A. and Osterloch, I.H. (1998) Clinical Safety of Oral Sildenafil Citrate (VIAGRA) in the Treatment of Erectile Dysfunction. International Journal of Impotence Research, 10, 69-73.

https://doi.org/10.1038/sj.ijir.3900354

[20] Cerrada, E., O’Connor Basalo, I., García de Blas González, F., et al. (2001) Effectiveness of Sildenafil in Primary Care. MEDIFAM, 11, 383-389.

[21] Torres Fuentes, G., Brito Herrera, B. and Montoya Sánchez, X. (2010) Use of Sildenafil for Erectile Dysfunction. Journal of Medical Sciences Havana, 16, 11 p.

[22] Cheitlin, M.D., et al. (1999) The ACC/AHA Expert Consensus Document "Use of Sildenafil (Viagra) in Patients with Cardiovascular Disease". Journal of the American College of Cardiology, 33, 273-282. https://doi.org/10.1016/S0735-1097(98)00656-1

[23] Raja, S.G. and Nayak, S.H. (2004) Sildenafil: Emerging Cardiovascular Indications. Annals of Thoracic Surgery, 78, 1496-1506. https://doi.org/10.1016/j.athoracsur.2004.02.125 